\title{
Author Correction: Limitation of Fermi level shifts by polaron defect states in hematite photoelectrodes
}

\author{
Christian Lohaus ${ }^{1}$, Andreas Klein (1) ${ }^{1}$ \& Wolfram Jaegermann ${ }^{1}$
}

Correction to: Nature Communications; https://doi.org/10.1038/s41467-018-06838-2, published online 17 October 2018

The original version of this Article contained an error in Fig. $2 \mathrm{~b}$ in which the bottom of the pink-shaded conduction band region was incorrectly positioned at a value of $1.75 \mathrm{eV}$. The correct conduction band minimum has a value of $2.2 \mathrm{eV}$. This has now been corrected in both the PDF and HTML versions of the Article.

Published online: 12 November 2018

\begin{abstract}
(c) (i) Open Access This article is licensed under a Creative Commons Attribution 4.0 International License, which permits use, sharing, adaptation, distribution and reproduction in any medium or format, as long as you give appropriate credit to the original author(s) and the source, provide a link to the Creative Commons license,

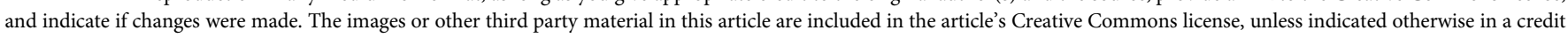
line to the material. If material is not included in the article's Creative Commons license and your intended use is not permitted by statutory regulation or exceeds the permitted use, you will need to obtain permission directly from the copyright holder. To view a copy of this license, visit http://creativecommons.org/licenses/by/4.0/.
\end{abstract}

(C) The Author(s) 2018 